\title{
Assessment of Radiotherapy Toxicity in Irradiated Internal Mammary Lymph Nodes in Breast Cancer Patients
}

\author{
Ahmed Ashour ${ }^{* 1}$ MSc, Wael El-Sheshtawy ${ }^{1}$ MD, Khalid El-Shahat ${ }^{1}$ Ph.D., Ahmed El-Agamawy ${ }^{1}$ MD
}

\author{
*Corresponding Author \\ Ahmed Ashour \\ ahmed.ashour@azhar.edu.eg \\ Received for publication April 8, \\ 2020; Accepted June 4, 2020; \\ Published online June 5, 2020 \\ Copyright 2020 The Authors published \\ by Al-Azhar University, Faculty of \\ Medicine, Cairo, Egypt. All rights \\ reserved. This an open-access article \\ distributed under the legal terms, where \\ it is permissible to download and share \\ the work provided it is properly cited. \\ The work cannot be changed in any \\ way or used commercially. \\ doi: 10.21608/aimj.2020.27527.1194 \\ ${ }^{I}$ Clinical Oncology \& Nuclear \\ Medicine Department, Faculty of \\ Medicine, Al-Azhar University, Cairo, \\ Egypt
}

\begin{abstract}
Background: breast cancer is the most prevalent cancer diagnosed in females worldwide. Radiotherapy improves survival in breast cancer patients. Consistent evidence emerges as regard the benefit of inclusion of IMN (internal mammary lymph nodes). Novel radiation techniques decreased the incidence of toxicity from radiotherapy.

Aim of the work: Assessment of acute and moderately late radiation toxicity, assessing doses to normal structures, assessing overall survival and progression-free survival.

Patients and Methods: this study included 41 patient received postoperative radiotherapy including internal mammary lymph nodes with Intensity-modulated radiation therapy in Al-Hussein University hospital

Results: coverage of the right-sided planning target volume and internal mammary lymph nodes was significantly higher than leftsided cases $p=0.01,95 \%, p=0.02$, respectively. there was a strong, positive correlation between the volume of heart receiving $25 \mathrm{~Gy}$ and the volume of planning target volume receiving $95 \%$ of the prescribed dose, $p=0.001$. Significant difference skin toxicity as regard maximum dose reaching the planning target volume either $\leq$ $107 \%, 108-109 \%$, and those $\geq 110, P=0.001$.

Conclusion: The inclusion of the internal mammary lymph nodes in postoperative radiotherapy in breast cancer patients is well tolerable. The use of Intensity-modulated radiation therapy decreases dose to normal structures which reduce toxicity
\end{abstract}

Keywords: Breast; IMN; Radiation; Toxicity

Disclosure: The authors have no financial interest to declare in relation to the content of this article. The Article Processing Charge was paid for by the authors.

Authorship: All authors have a substantial contribution to the article

\section{INTRODUCTION}

The advances in adjuvant systemic treatment for breast cancer have decreased the risk of death from distant metastasis significantly. ${ }^{1}$ On the other hand, remarkable consistent local control advantage has been denoted in multiple randomized phases 3 trials designed to assess the role of adjuvant radiation in breast cancer patients. ${ }^{2}$ with lacking survival benefit until the publication of the Early Breast Cancer Trialists' Collaborative Group (EBCTCG) metaanalysis that showed a reduction in the 15 -year risk of breast cancer death $(21 \%$ versus $25 \%$, RR 0.82 , 95\% CI 0.75-0.90). ${ }^{3}$

In this metanalysis, internal mammary lymph nodes (IMN) treatment were included in 24 of the 25 postmastectomy radiation therapy studies included in
EBCTCG meta-analysis, which led to renewed enthusiasm in IMN treatment in the current management of breast cancer. ${ }^{3}$

Based on the results from two large clinical studies (EORTC 22922/10925 and MA.20) that showed, at a median follow-up of around 10 years, very similar results, with an increase in disease-free survival $(72.1 \%$ vs $69.1 \%$, HR $0.89, \mathrm{p}=0.04)$ and $(82 \%$ vs. $82 \%$, HR $0.76, \mathrm{p}=0.01)$ respectively and distant disease-free survival $(78 \%$ vs. $75 \%$, HR $0.86, \mathrm{p}=$ $0.02)$ and $(86.3 \%$ vs $82.4 \%$, HR $0.76, p=0.03)$ respectively with the trend towards overall survival in EORTC trial, 4,5 starting 2016 the National Comprehensive Cancer Network (NCCN) guidelines raised power for the recommendation of irradiation of IMNs in patients with 1-3 positive axillary lymph 
nodes (ALNs) (category 2A), following mastectomy and lumpectomy. ${ }^{6}$

One of the most crucial concerns about internal mammary lymph nodes irradiation (IMNI) is the increased radiation dose to the heart and lungs when outdated techniques have been used. Long term follow up of randomized clinical trials has proved that irradiation exposure of the heart during breast cancer radiotherapy would increase the future risk of heart disease. ${ }^{7}$

With the development of modern radiotherapy techniques, irradiation dose to heart and lung from breast radiotherapy have decreased during recent decades. Intensity-modulated radiotherapy (IMRT) has shown encouraging results as a heart and lungsparing technique for breast cancer patients in several studies. $8,9,10,11$

In this study, we have evaluated the feasibility of inclusion of the IMN with reverse planning IMRT with dosimetric evaluation and toxicity profile.

\section{PATIENTS AND METHODS}

From February 2014 through December 2018, fortyone patients were enrolled in this study. Eligibility criteria included adult females with histopathologically confirmed breast cancer with positive ALNs or medially located tumors irrespective of axillary involvement. Patients were assigned to receive postoperative radiation therapy (PORT) to breast/ chest-wall and lymphatics, including IMNs at a dose of 50 Gray (Gy) in 25 fractions. Delineation was done according to the RTOG guidelines for the delineation of target and normal structures for breast cancer. All patients received inverse planning IMRT using Eclipse commercial planning system version 14.6 with Varian Unique treatment unit.

Treatment-related toxicity was evaluated using the NCI Common Terminology Criteria for Adverse Events (CTCAE) version 4. The primary endpoint was the assessment of acute and moderately late toxicity. the secondary endpoint was the estimation of radiation dose to normal structures, and the tertiary endpoint was progression-free survival (PFS) and overall survival (OS). Overall survival was calculated from the date of histopathological diagnosis to the date of death from any cause. Disease-free survival was calculated from the date of histopathological diagnosis to the first date of local recurrence, regional recurrence, distant recurrence. Local recurrence-free survival was calculated from the date of histopathological diagnosis to the first date of local recurrence or regional recurrence. Statistical package SPSS version 26 was used in processing data using mean, standard deviation, median, minimum, and maximum for quantitative variables and frequencies (number of cases) and relative frequencies (percentages) for categorical variables. One-sided log-rank of Kaplan-Meier survival estimates was used for statistical analysis of OS and PFS, unpaired T-test, and fisher's exact test was used in the univariate analysis of the variables. Results of the P-value less than 0.05 were considered statistically significant.
The current study had been approved by the ethical committee, Faculty of Medicine, Al-Azhar University, before the start of the work.

\section{RESULTS}

This study included 41 patients with median age 50 years range (29 - 63), postmenopausal women represent $(58.5 \%)$. most patients had the right-sided disease $(78 \%), 7$ patients $(17.1 \%)$ had UIQ disease location, 6 patients $(14.6 \%)$ had a central disease, while none had LIQ disease. (92\%) of patients subjected to MRM and only (7.7\%) subjected to CBS. (Table 1)

\begin{tabular}{|c|c|c|}
\hline \multirow{2}{*}{$\begin{array}{ll} & \text { Factors } \\
\underline{\text { Age }} & \end{array}$} & \multicolumn{2}{|c|}{ Total $n=41$} \\
\hline & mean & $S D$ \\
\hline & 49.1 & 8.201 \\
\hline & median & $(\operatorname{Min}-\operatorname{Max})$ \\
\hline & 50 & $29-63$ \\
\hline Menopausal status & $\mathrm{N}$ & $\%$ \\
\hline premenopausal & 17 & 3.13 \\
\hline postmenopausal & 24 & 58.5 \\
\hline Premenopausal age & mean & SD \\
\hline & 44.5 & 6.331 \\
\hline & median & (Min-Max) \\
\hline & 46 & $29-52$ \\
\hline Postmenopausal age & mean & SD \\
\hline & 56.35 & 4.808 \\
\hline & median & (Min-Max) \\
\hline & 57 & $47-63$ \\
\hline comorbidity & $\mathrm{N}=41$ & $\%$ \\
\hline DM, HTN \& IHD & 1 & 2.4 \\
\hline DM \& HTN & 2 & 4.9 \\
\hline DM & 11 & 26.8 \\
\hline HTN & 7 & 17.1 \\
\hline IHD & 1 & 2.4 \\
\hline$\underline{\text { Disease Side }}$ & $\mathrm{N}=41$ & $\%$ \\
\hline Right breast & 32 & 78 \\
\hline Left breast & 9 & 22 \\
\hline Surgery type & $\mathrm{N}=41$ & $\%$ \\
\hline MRM & 38 & 92.7 \\
\hline CBS & 3 & 7.7 \\
\hline Histopathology & $N=41$ & $\%$ \\
\hline IDC & 39 & 95.1 \\
\hline Mixed & 2 & 4.9 \\
\hline G II & 38 & 92.7 \\
\hline GIII & 3 & 7.3 \\
\hline ER +ve & 31 & 75.6 \\
\hline ER -ve & 10 & 24.4 \\
\hline Her2 nue +ve & 10 & 24.4 \\
\hline Her2 nue -ve & 31 & 75.6 \\
\hline Triple -ve & 5 & 12.2 \\
\hline Staging & $\mathrm{N}=41$ & $\%$ \\
\hline IIA & 1 & 2.4 \\
\hline IIIA & 24 & 61.5 \\
\hline IIIB & 2 & 5.1 \\
\hline IIIC & 12 & 30.7 \\
\hline
\end{tabular}


Table (1): Clinicopathological data of the patients

Dosimetric Parameters

Planning target volume that received $95 \%$ of the prescribed dose (PTV95) had mean coverage of $92.53 \%(86.3-98.3)$ and a mean dose of $100.2 \%$ $(98.2$ - 102) with a maximum dose (PTVmax) of $108.9 \%$ (106.5 - 111). Table 2

\begin{tabular}{|c|c|c|}
\hline \multirow{2}{*}{$\begin{array}{l}\text { Factors } \\
\text { PTV95 }\end{array}$} & \multicolumn{2}{|c|}{ Total $n=41$} \\
\hline & mean & $S D$ \\
\hline & 92.5 & 2.97 \\
\hline & median & (Min-Max) \\
\hline & 93 & $86.3-98.3$ \\
\hline \multirow[t]{4}{*}{ PTV93 } & mean & $S D$ \\
\hline & 95.1 & 2.33 \\
\hline & median & (Min-Max) \\
\hline & 95.2 & $89.1-99.1$ \\
\hline \multirow[t]{4}{*}{ PTV90 } & mean & $S D$ \\
\hline & 97.4 & 1.8 \\
\hline & median & (Min-Max) \\
\hline & 97.8 & $92-99.9$ \\
\hline \multirow[t]{4}{*}{ PTV Dmean } & mean & $S D$ \\
\hline & 100.2 & 0.45 \\
\hline & median & (Min-Max) \\
\hline & 100.2 & $98.2-102$ \\
\hline \multirow[t]{4}{*}{$\underline{\text { PTV Dmax }}$} & mean & $S D$ \\
\hline & 108.9 & 0.69 \\
\hline & median & (Min-Max) \\
\hline & 109.2 & $106.5-111$ \\
\hline
\end{tabular}

Table 2: PTV coverage in \%

PTV95 for right-sided cases was covered by higher average dose $(93.36 \%, S D=2.618)$ as compared to left side PTV95 $(89.66 \%, S D=2.403), p=0.01,95 \%$ C.I. [1.714 - 5.645]. no significant difference in mean dose coverage as regard PTV for right-sided cases $(50.18 \mathrm{~Gy}, S D=0.459)$ as compared to leftsided cases (49.89 Gy $S D=0.839), p=0.085,95 \%$ C.I. $[-0.042-0.628]$.

Ninety-five percent of the IMN had mean dose coverage of $87.36 \%$, with a median $90.5(50-99.8)$. $90 \%$ IMN volume had mean coverage $94.2 \%$ (60$100)$ of the prescribed dose. With mean dose for IMN 49.23 Gy $(40.3$ - 51.7).

The ninety-five percent of IMN for right sided cases are covered by higher average dose $(90.87 \%, S D=$ $7.869)$ as compared to left side coverage (74.9\%, SD $=16.47), p=0.02,95 \%$ C.I. [3.167 - 28.774]. there was no significant difference in mean dose reaching IMN for right-sided cases $(49.67 \mathrm{~Gy}, S D=1.27)$ as compared to left-sided cases $(47.63$ Gy $S D=3.28), p$ $=0.10,95 \%$ C.I. $[-0.498-4.578]$.

The mean volume that received $\geq 20$ Gy of the ipsilateral lung (V20) was $25.83 \%(18.5-29.9)$ with percentile $9528.2 \%$ meaning that $95 \%$ of cases have lung V20 below $28.2 \%$. Table 3

\begin{tabular}{|c|c|c|}
\hline Factors & \multicolumn{2}{|c|}{ Total $n=41$} \\
\hline \multirow[t]{6}{*}{ Lung V20 } & mean & $S D$ \\
\hline & 25.8 & 2.62 \\
\hline & median & $($ Min-Max) \\
\hline & 26.3 & $18.5-29.9$ \\
\hline & \multicolumn{2}{|c|}{ Percentile 95} \\
\hline & \multicolumn{2}{|c|}{28.2} \\
\hline \multirow[t]{6}{*}{ Lung V10 } & mean & $S D$ \\
\hline & 45.5 & 6.1 \\
\hline & median & $($ Min-Max) \\
\hline & 46.2 & $32.5-60.2$ \\
\hline & \multicolumn{2}{|c|}{ Percentile 95} \\
\hline & \multicolumn{2}{|c|}{54.1} \\
\hline \multirow[t]{6}{*}{ Lung V5 } & mean & $S D$ \\
\hline & 73.2 & 8.86 \\
\hline & median & $($ Min-Max) \\
\hline & 70.2 & $50.1-88.6$ \\
\hline & \multicolumn{2}{|c|}{ Percentile 95} \\
\hline & \multicolumn{2}{|c|}{87.3} \\
\hline \multirow[t]{6}{*}{ MLD } & mean & $S D$ \\
\hline & 14.08 & 0.79 \\
\hline & median & $($ Min-Max) \\
\hline & 14.2 & $12.1-15.7$ \\
\hline & \multicolumn{2}{|c|}{ Percentile 95} \\
\hline & \multicolumn{2}{|c|}{15.4} \\
\hline
\end{tabular}

Table 3: Ipsilateral lung dose

Lung V20 for right sided cases had no significantly higher dose $(26.12 \mathrm{~Gy}, S D=2.11)$ as compared to left side ipsilateral lung V20 (24.81 Gy, $S D=3.98)$, $p=0.36,95 \%$ C.I. [-0.68 - 3.29]. Mean lung dose (MLD) for right-sided cases had no significantly higher dose $(14.14 \mathrm{~Gy}, S D=0.75)$ as compared to left-side ipsilateral mean lung dose (13.86 Gy, $S D=$ $098), p=0.358,95 \%$ C.I. [-0.329 - 0.892].

The mean volume of the heart that received $\geq 25$ Gy (Heart V25) was $2.71(0.3-12.1)$, while the mean heart dose was $5.24 \mathrm{~Gy},(2-9.7)$. Heart V25 for right sided cases was significantly low $(1.15 \%, S D=0.61)$ as compared to left side heart V25 $(8.27 \% S D=$ $3.46), p=0.001,95 \%$ C.I. [-9.78 - -4.45]. For rightsided cases the heart received significantly lower mean doses (4.5 Gy, $S D=1.79)$ as compared to leftsided cases $(7.8$ Gy $S D=1.85), p=0.001,95 \%$ C.I. [-4.709- -1.955].

A Pearson product-moment correlation coefficient was computed to assess the relationship between heart V25 and (PTV V95 and IMN V95). There was a positive correlation between the variables, $(\mathrm{r}=$ $0.463, \mathrm{n}=41, \mathrm{p}=0.002)$ and $(\mathrm{r}=-0.491, \mathrm{n}=41, \mathrm{p}=$ $0.001)$ respectively. There was no significant correlation between Heart V25 and IMN distance, (r $=-0.198, \mathrm{n}=41, \mathrm{p}=0.215$ ). other normal structure doses are summarized in Table 4 


\begin{tabular}{|l|l|l|}
\hline Factors & \multicolumn{2}{l}{ Total $\mathbf{n}=\mathbf{4 1}$} \\
\hline Contralateral Breast, & mean & SD \\
\hline Dmean & 3.76 & 1.14 \\
& median & (Min-Max) \\
\hline Esophagus, Dmean & 4 & $0.5-5.6$ \\
\hline & mean & SD \\
\hline & 16.6 & 4.03 \\
\hline & median & $($ Min-Max $)$ \\
\hline Brachial Plexus, & 17 & $4.7-23$ \\
\hline & mean & SD \\
\hline & 48.8 & 4.49 \\
\hline & median & $($ Min-Max $)$ \\
\hline & 50 & $30.2-53.2$ \\
\hline Thyroid, Dmean & mean & SD \\
\hline & 30.9 & 4.19 \\
\hline & median & (Min-Max) \\
\hline & 31 & $23.8-40.5$ \\
\hline
\end{tabular}

Table 4: Normal tissue doses per Gy (contralateral breast, esophagus, brachial plexus, and thyroid)

Treatment-related Toxicity

Eighteen patients (43.9\%) had GI erythema, while G II erythema was seen in 23 patients $(56.1 \%)$, most patients recovered within two weeks and all patients recovered within one month.

GI and II skin desquamation was seen in 20 patients (48.8\%) and 4 patients $(9.8 \%)$ respectively, while GIII was seen in one patient (2.4\%). Infection was seen in $(2.4 \%)$. Tables 5, 6

Pruritis was seen in (19.5\%) of patients; also, esophagitis was seen in (19.5\%) of patients

\begin{tabular}{|l|l|l|}
\hline \multirow{2}{*}{ Factors } & \multicolumn{2}{c}{ Total n $\mathbf{4 1}$} \\
\hline Week 1 & N & $\%$ \\
\hline G0 & 41 & 100 \\
\hline Week 2 & & \\
\hline G0 & 37 & 90.2 \\
\hline GI & 4 & 9.8 \\
\hline Week 3 & 18 & 43.9 \\
\hline G0 & 23 & 56.1 \\
\hline GI & & \\
\hline Week 4 & 1 & 2.4 \\
\hline G0 & 37 & 90.2 \\
\hline GI & & 7.3 \\
\hline GII & & \\
\hline
\end{tabular}

\begin{tabular}{|l|l|l|}
\hline Week 5 & & \\
\hline GI & 18 & 43.9 \\
\hline GII & 23 & 56.1 \\
\hline Week 6 & & \\
\hline GII & 4 & 100 \\
\hline Week +1 & & \\
\hline G0 & 2 & 4.9 \\
\hline GI & 37 & 90.2 \\
\hline GII & 2 & 4.9 \\
\hline Month 1 & & \\
\hline G0 & 41 & 100 \\
\hline
\end{tabular}

Table 5: Skin erythema during and after radiation.

\begin{tabular}{|c|c|c|}
\hline \multirow[t]{2}{*}{ Factors } & \multicolumn{2}{|c|}{ Total $n=41$} \\
\hline & $\mathbf{N}$ & $\%$ \\
\hline \multicolumn{3}{|l|}{ Week 1} \\
\hline G0 & 41 & 100 \\
\hline \multicolumn{3}{|l|}{ Week 2} \\
\hline G0 & 41 & 100 \\
\hline \multicolumn{3}{|l|}{ Week 3} \\
\hline G0 & 29 & 70.7 \\
\hline GI & 12 & 29.3 \\
\hline \multicolumn{3}{|l|}{ Week 4} \\
\hline G0 & 24 & 58.5 \\
\hline GI & 17 & 41.5 \\
\hline \multicolumn{3}{|l|}{ Week 5} \\
\hline G0 & 16 & 39 \\
\hline GI & 20 & 48.8 \\
\hline GII & 4 & 9.8 \\
\hline GIII & 1 & 2.4 \\
\hline \multicolumn{3}{|l|}{ Week 6} \\
\hline GI & 4 & 100 \\
\hline Week +1 & & \\
\hline
\end{tabular}




\begin{tabular}{|l|c|c|}
\hline G0 & 23 & 56.1 \\
\hline GI & 18 & 43.9 \\
\hline Month 1 & & \\
\hline G0 & 37 & 90.2 \\
\hline GI & 4 & 9.8 \\
\hline
\end{tabular}

Table 6: Skin desquamation during and after radiation.

Univariate analysis showed a significant difference between different skin toxicity grades between patients as regard PTVmax either $\leq 107,108-109$, and those with PTVmax $\geq 110$, fishers exact test $P=$ 0.001 , Skin toxicity is increasing with the increase of the maximum dose to PTV. Table 7

\begin{tabular}{|c|c|c|c|c|c|c|c|}
\hline & \multicolumn{2}{|c|}{ G2 } & \multicolumn{3}{|l|}{ G3 } & \multicolumn{2}{|c|}{ P-value } \\
\hline & $\mathrm{N}$ & $\%$ & $\mathrm{~N}$ & $\%$ & $\mathrm{~N}$ & $\%$ & \\
\hline \multicolumn{8}{|l|}{ Tumor sites } \\
\hline Left breast & 5 & 12.1 & 4 & 9.7 & 0 & 0 & 0.770 \\
\hline Right breast & 13 & 31.7 & 18 & 43.9 & 1 & 2.4 & \\
\hline \multicolumn{8}{|l|}{$\begin{array}{l}\text { Molecular } \\
\text { subtypes }\end{array}$} \\
\hline Luminal B & 13 & 31.7 & 12 & 29.2 & 0 & 0 & 0.418 \\
\hline $\begin{array}{l}\text { HER-2 } \\
\text { enriched }\end{array}$ & 3 & 7.3 & 6 & 68.6 & 1 & 2.4 & \\
\hline $\begin{array}{l}\text { Triple- } \\
\text { negative }\end{array}$ & 2 & 4.8 & 4 & 71.4 & 0 & 0 & \\
\hline \multicolumn{8}{|l|}{ Age, years } \\
\hline$<40$ & 2 & 4.8 & 3 & 7.3 & 0 & 0.0 & 0.903 \\
\hline $40-60$ & 13 & 31.7 & 17 & 41.5 & 1 & 2.4 & \\
\hline$>60$ & 3 & 7.3 & 2 & 4.8 & 0 & 0 & \\
\hline \multicolumn{8}{|l|}{$\begin{array}{l}\text { Types of } \\
\text { surgery }\end{array}$} \\
\hline Lumpectomy & 0 & 0 & 3 & 7.3 & 0 & 0 & 0.294 \\
\hline Mastectomy & 18 & 43.9 & 19 & 46.3 & 1 & 2.4 & \\
\hline \multicolumn{8}{|l|}{$P T V \max$} \\
\hline Tomax $\leq 107$ & 5 & 12.2 & 2 & 4.8 & 1 & 2.4 & $0.001^{*}$ \\
\hline $\begin{array}{l}\text { Tomax } 108 \text { - } \\
109\end{array}$ & 12 & 29.3 & 2 & 4.8 & 18 & 43.9 & \\
\hline $\begin{array}{l}P T V \max \\
\geq 110\end{array}$ & 1 & 2.4 & 0 & 0 & 0 & 0 & \\
\hline \multicolumn{8}{|l|}{$\overline{I M N}$ distance } \\
\hline $10-14 \mathrm{~mm}$ & 5 & 12.2 & 1 & 2.4 & 0 & 0 & 0.249 \\
\hline $15-19 \mathrm{~mm}$ & 12 & 29.3 & 19 & 46.3 & 1 & 2.4 & \\
\hline$\geq 20 \mathrm{~mm}$ & 1 & 2.4 & 2 & 4.8 & 0 & 0 & \\
\hline \multicolumn{8}{|l|}{ T. bed Boost } \\
\hline Boost & 0 & 0 & 4 & 9.7 & 0 & 0 & 0.2 \\
\hline No Boost & 18 & 43.9 & 18 & 43.9 & 1 & 2.4 & \\
\hline
\end{tabular}

Table 7: Maximal radiation dermatitis grade related to the clinicopathologic characteristics, assessed by radiation therapy oncology group score

None of the patients experienced Acute pulmonary symptoms during radiation treatment time. Also, lung fibrosis was not detected in CT images that were done for follow up purposes. None of the patients had cardiac events.

After a median follow-up 26 months, one patient (2.4\%) had a relapse in chest-wall, 4 patients $(9.8 \%)$ had a distant relapse to lung, and/or liver Median overall survival and median progression-free survival were not reached. Figures 1,2

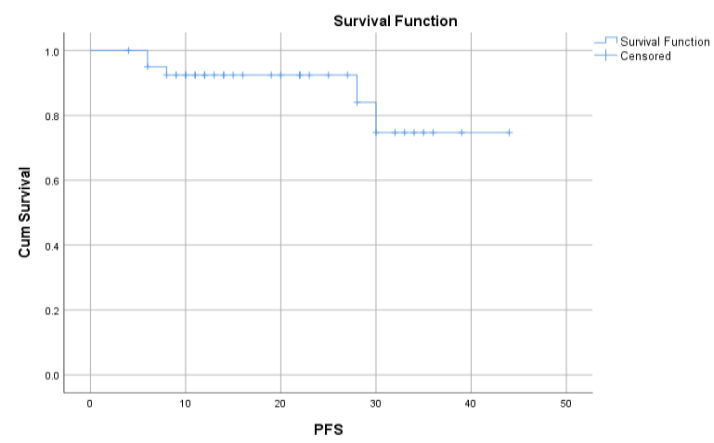

Figure (1): Kaplan Meier survival curve for PFS time

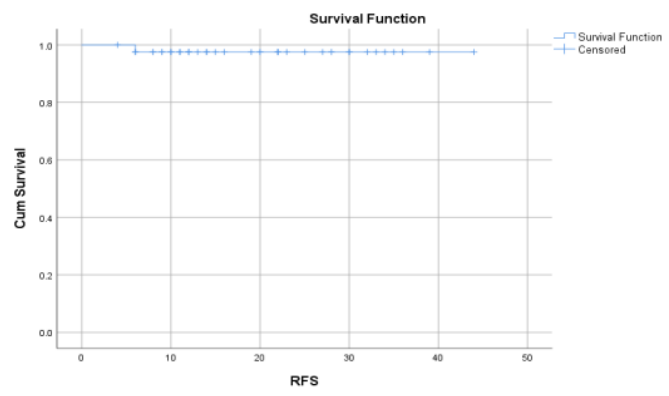

Figure (2): Kaplan-Meier survival curve for PFS time

\section{DISCUSSION}

The optimum management of IMNs in breast cancer is controversial. However, there is increasing evidence that the inclusion of IMNs as a target in regional nodal irradiation (RNI) has the potential to reduce local recurrence, distant recurrence, and improve long-term survival in breast cancer patients.

The current indications of internal mammary adjuvant irradiation are patients with $\geq$ four positive ALNs, medial tumors, and positive ALNs,${ }^{13}$ we have adopted these indications for IMC irradiation for patients included in this study.

Many radiotherapy techniques have been used to deliver radiation to the IMC, including electron or electron/photon fields matched to shallow photon tangents, partially wide photon tangents, proton therapy, and IMRT or volumetric modulated arc therapy (VMAT). ${ }^{14,15,16}$

The most commonly adopted IMRT technique for adjuvant breast irradiation is the planning IMRT that use the simple field in field technique, while the inverse planning IMRT may offer some advantage in patients who have complicated radiotherapy plans like those who are going to receive IMC irradiation (as patients included in our study) or patients with abnormal chest wall shape.

On the other hand inclusion of IMN in PORT fields raise the concern of increased toxicity to lung, heart, and contralateral breast due to the higher radiation doses to these structures, however, the IMRT 
technique may provide a way to balance coverage of IMN and decreasing the doses to organs at risk. ${ }^{17}$ The concern about cardiac toxicity came after the observation of increase cardiac mortality rates by about $30 \%$ at 10 years in patients receiving adjuvant left breast irradiation due to coronary arteries irradiation, especially the left anterior descending (LAD) coronary artery, ${ }^{18}$ volume of the heart that receives $\geq 25$ Gy (V25) should be limited to $<10 \%$ according to the QUANTEC criteria for cardiac tolerance, this dose tolerance has shown clinical correlation to the incidence of IHD and cardiac mortality in a recent study, ${ }^{19}$ in our study the heart V25 were within the tolerance for all patients, which suggesting acceptable cardiac sparing with IMRT technique in left-sided patients.

Several other techniques were proposed for decreasing heart dose, including Breathing-adapted radiotherapy, ${ }^{20}$ prone positions, especially for patients with pendulous breast, ${ }^{21}$, and Partial-breast $\mathrm{RT}$ in elderly patients with low-risk disease. ${ }^{22}$, in this study we did not use any of these techniques with the IMRT.

Homogenous coverage of the PTV during adjuvant breast irradiation is a major concern, the Last ASRTO guidelines recommending a dose coverage ranging between $95 \%$ and $107 \%$ to at least $95 \%$ of the PTV and considered no more than $200 \mathrm{cc}>105 \%$ and $2 \mathrm{cc}>107 \%$, a reasonable goal for most cases. ${ }^{23}$ Our patient study group have mean PTV V95\% coverage $=92.5 \%$ and mean PTV Dmax $=109 \%$. Many studies have found less desquamation when the maximum PTV dose is limited to $105 \%$ or $107 \%$ of the prescription dose. ${ }^{24,25,}{ }^{26}$ although the PTV DMax in this study was 109 the rate of acute skin toxicity was $56.1 \%$ for grade 2 dermatitis while $9.8 \%$ have wet desquamation only one patient had grade 3 dermatitis, most patients recovered after two weeks which is considered acceptable.

Because of the limited number of patients, only skin toxicity was significantly increased with an increased maximum dose of radiation to the planning target volume, also with this limited number, pulmonary toxicity and cardiac toxicity were not encountered in our patients because of the rarity of these events in general.

\section{CONCLUSION}

The inclusion of the IMN in PMRT is well tolerable. The use of inverse planning IMRT when IMC is going to be treated could be justified to decrease toxicity to the heart, lung and contralateral breast in selected patients even if they have MRM, However, the decision of inclusion of IMC must be individualized taking in count the available radiation techniques and the patient expected morbidity and mortality.

\section{REFERENCES}

1. Harbeck N, Penault-Llorca F, Cortes J, et al. Breast cancer. Nat Rev Dis Prim. 2019;5(1):1-31. doi:10.1038/s41572-0190111-2

2. Remick J, Amin NP. Postmastectomy Breast Cancer Radiation Therapy.
StatPearls Publishing

2019.

http://www.ncbi.nlm.nih.gov/pubmed/30085

576. Accessed March 25, 2020.

3. Darby S, McGale P, Correa C, et al. Effect of radiotherapy after breast-conserving surgery on 10-year recurrence and 15- year breast cancer death: Meta-analysis of individual patient data for 10801 women in 17 randomised trials. Lancet. 2011;378(9804):1707-1716. doi:10.1016/S0140-6736(11)61629-2

4. Poortmans PM, Collette S, Kirkove C, et al. Internal mammary and medial supraclavicular irradiation in breast cancer. N Engl J Med. 2015;373(4):317-327. doi:10.1056/NEJMoa1415369

5. Whelan TJ, Olivotto IA, Parulekar WR, et al. Regional nodal irradiation in early-stage breast cancer. $N$ Engl J Med. 2015;373(4):307-316.

6. Gradishar WJ, Anderson BO, Balassanian $\mathrm{R}$, et al. Invasive breast cancer version 1.2016. JNCCN J Natl Compr Cancer Netw. 2016;14(3):324-354. doi:10.6004/jncen.2016.0037

7. Choi J, Kim YB, Shin KH, et al. Radiation pneumonitis in association with internal mammary node irradiation in breast cancer patients: An ancillary result from the KROG 08-06 study. J Breast Cancer. 2016;19(3):275-282.

doi:10.4048/jbc.2016.19.3.275

8. Shah C, Badiyan S, Berry S, et al. Cardiac dose sparing and avoidance techniques in breast cancer radiotherapy. Radiother Oncol. 2014;112(1):9-16. doi:10.1016/j.radonc.2014.04.009

9. Caudrelier JM, Meng J, Esche B, Grimard L, Ruddy T, Amjadi K. IMRT sparing of normal tissues in locoregional treatment of breast cancer. Radiat Oncol. 2014;9(1):1-7. doi:10.1186/1748-717X-9-161

10. Li J, Wang X, Ma J, Yu X, Guo X, Zhang

Z. Prospective evaluation of skin toxicities in patients receiving post-mastectomy irradiation of chest wall, supra/infraclavicular and internal mammary nodes delivered by conventional versus intensity-modulated radiotherapy technique. Oncotarget. 2017;8(45):8001280019. doi:10.18632/oncotarget.20820

11. Ho AY, Ballangrud A, Li G, et al. LongTerm Pulmonary Outcomes of a Feasibility Study of Inverse-Planned, Multibeam Intensity Modulated Radiation Therapy in Node-Positive Breast Cancer Patients Receiving Regional Nodal Irradiation. Int $J$ Radiat Oncol Biol Phys. 2019;103(5):11001108. doi:10.1016/j.ijrobp.2018.11.045

12. Thorsen LBJ, Offersen BV, Danø H, et al. DBCG-IMN: A population-based cohort study on the effect of internal mammary node irradiation in early node-positive breast cancer. J Clin Oncol. 2016;34(4):314-320. 
doi:10.1200/JCO.2015.63.6456

13. Sprinks J. Treating breast cancer. NCCN Guidel Clin Resour. 2019;15(6):11-11. doi:10.7748/cnp.15.6.11.s11

14. Jagsi R, Moran J, Marsh R, Masi K, Griffith KA, Pierce LJ. Evaluation of four techniques using intensity-modulated radiation therapy for comprehensive locoregional irradiation of breast cancer. Int J Radiat Oncol Biol Phys. 2010;78(5):1594-1603. doi:10.1016/j.ijrobp.2010.04.072

15. Cuaron JJ, Chon B, Tsai H, et al. Early toxicity in patients treated with postoperative proton therapy for locally advanced breast cancer. Int J Radiat Oncol Biol Phys. 2015;92(2):284-291. doi:10.1016/j.ijrobp.2015.01.005

16. Ho AY, Ballangrud A, Li G, et al. LongTerm Pulmonary Outcomes of a Feasibility Study of Inverse-Planned, Multibeam Intensity Modulated Radiation Therapy in Node-Positive Breast Cancer Patients Receiving Regional Nodal Irradiation. Int J Radiat Oncol Biol Phys. 2019;103(5):11001108. doi:10.1016/j.ijrobp.2018.11.045

17. Song Y, Yu T, Wang W, et al. Dosimetric comparison of incidental radiation to the internal mammary nodes after breastconserving surgery using 3 techniquesinverse intensity-modulated radiotherapy, field-in-field intensity-modulated radiotherapy, and 3-dimensional conformal radiother. Med (United States). 2019;98(41):e17549. doi:10.1097/MD.0000000000017549

18. Cuzick J, Stewart H, Rutqvist L, et al. Cause-specific mortality in long-term survivors of breast cancer who participated in trials of radiotherapy. J Clin Oncol. 1994;12(3):447-453. doi:10.1200/JCO.1994.12.3.447

19. Marks LB, Yorke ED, Jackson A, et al. Use of Normal Tissue Complication Probability Models in the Clinic. Int $J$ Radiat Oncol Biol Phys. 2010;76(3 SUPPL.). doi:10.1016/j.ijrobp.2009.07.1754

20. Boda-Heggemann J, Knopf AC, Simeonova-Chergou A, et al. Deep Inspiration Breath Hold - Based Radiation Therapy: A Clinical Review. Int J Radiat Oncol Biol Phys. 2016;94(3):478-492. doi:10.1016/j.ijrobp.2015.11.049

21. Gerber NK, Yan SX, Levinson BA, et al. A prospective trial to compare deep inspiratory breath hold (DIBH) with prone breast irradiation. Pract Radiat Oncol. February 2020. doi:10.1016/j.prro.2020.01.001

22. Coles CE, Griffin CL, Kirby AM, et al. Partial-breast radiotherapy after breast conservation surgery for patients with early breast cancer (UK IMPORT LOW trial): 5- year results from a multicentre, randomised, controlled, phase 3, non-inferiority trial. Lancet. 2017;390(10099):1048-1060. doi:10.1016/S0140-6736(17)31145-5

23. Smith BD, Bellon JR, Blitzblau R, et al. Radiation therapy for the whole breast: Executive summary of an American Society for Radiation Oncology (ASTRO) evidence-based guideline. Pract Radiat Oncol. 2018;8(3):145-152.

doi:10.1016/j.prro.2018.01.012

24. Hardee ME, Raza S, Becker SJ, et al. Prone hypofractionated whole-breast radiotherapy without a boost to the tumor bed: comparable toxicity of IMRT versus a 3D conformal technique. Int J Radiat Oncol Biol Phys. 2012;82(3):e415-23.

doi:10.1016/j.ijrobp.2011.06.1950

25. Hannan R, Thompson RF, Chen Y, et al. Hypofractionated whole-breast radiation therapy: does breast size matter? Int J Radiat Oncol Biol Phys. 2012;84(4):894901. doi:10.1016/j.ijrobp.2012.01.093

26. Mukesh MB, Barnett GC, Wilkinson JS, et al. Randomized controlled trial of intensity-modulated radiotherapy for early breast cancer: 5 -year results confirm superior overall cosmesis. J Clin Oncol. 2013;31(36):4488-4495.

doi:10.1200/JCO.2013.49.7842 